$x-92174-250$

MAS I GEODETIC RESULTS FROM ISAGEX DATA

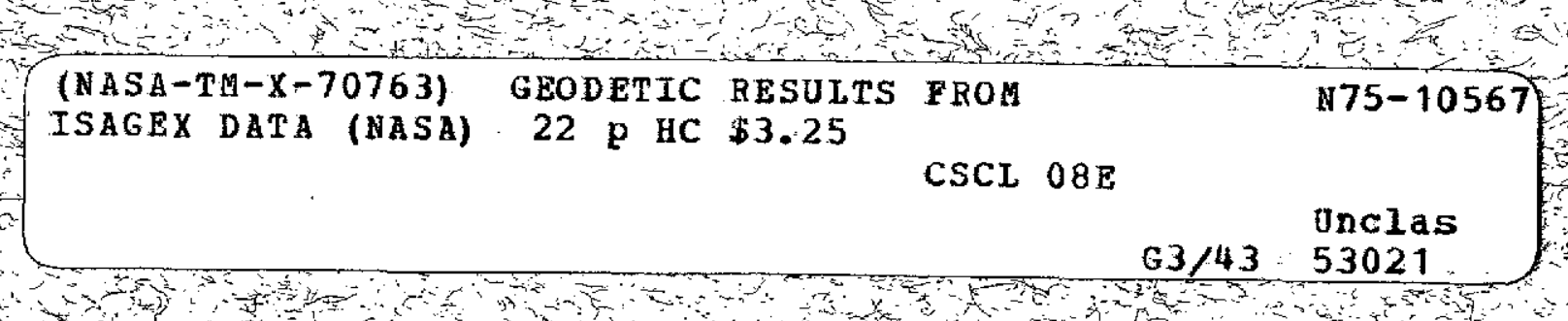

J. MARSH

B. DOUGLAS

D M WALLS

AUGUST 1974

GODDARD SPACE FLIGHT CENTER GREENBELT MARYLAND 


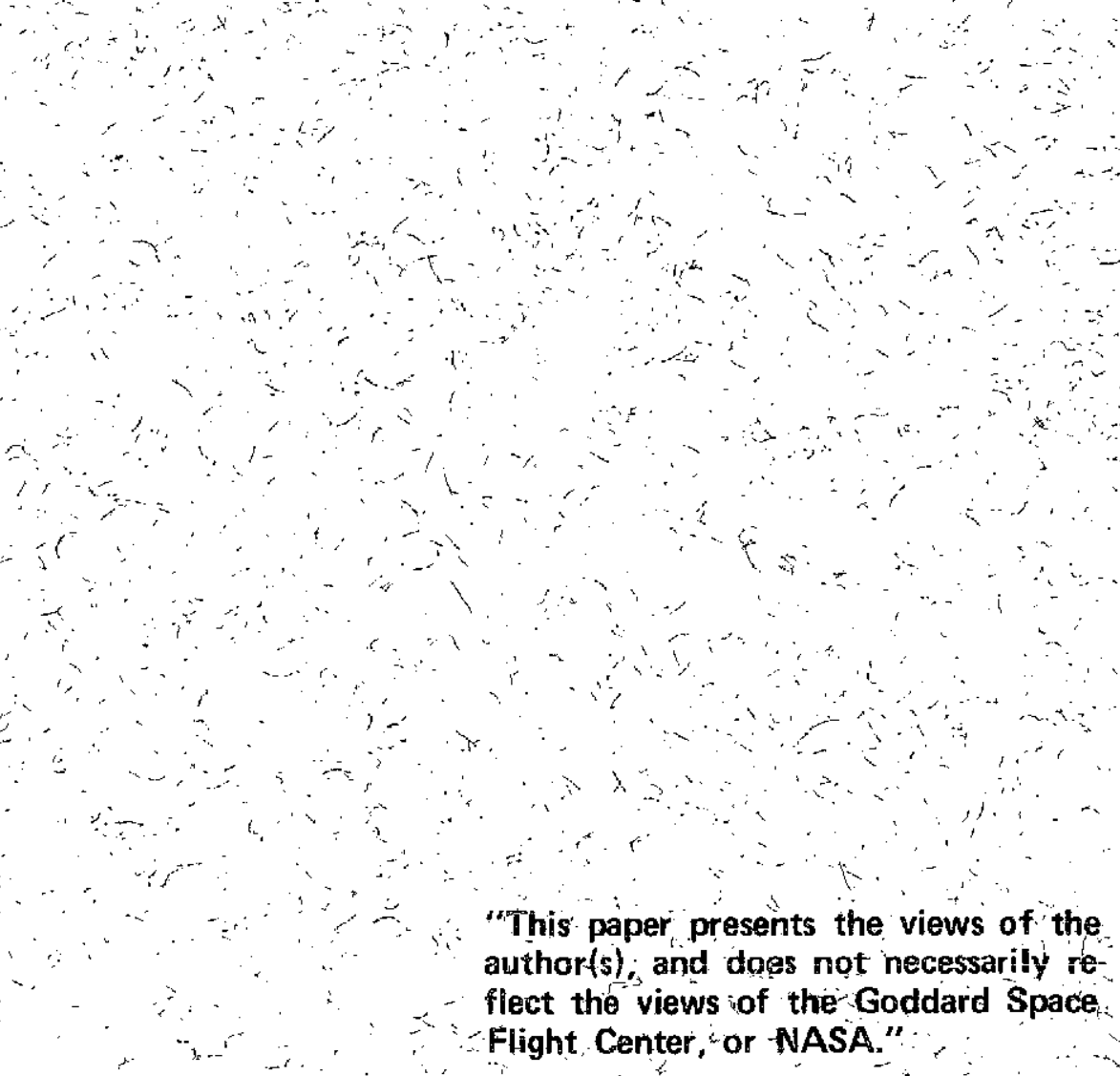

().

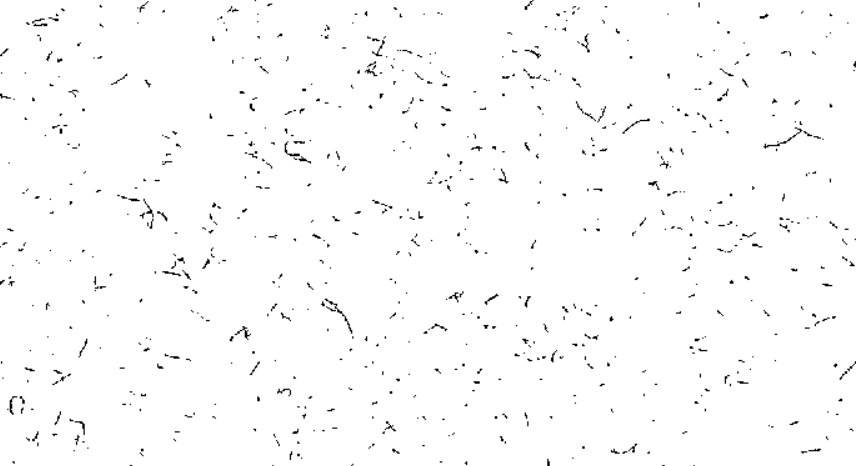

For information concerning availability of this documient contact:

Techniçal Informatión Division, Code 250 Goddard Space Flight Center

Greenbelt, Maryland 20771

(Telephone 301-982-4488) 


\title{
GEODETIC RESULTS FROM \\ ISAGEX DATA
}

\author{
J. G. Marsh \\ Goddard Space Flight Center \\ Greenbelt, Maryland \\ B. C. Douglas* \\ D. M. Walls \\ Wolf Research and Development Corporation \\ Riverdale, Maryland 20840
}

August 1974

*Presently with the National Oceanic and Atmospheric Administration/National Ocean Survey, Rockville, Maryland.

GODDARD SPACE FLIGHT CENTER

Greenbelt, Maryland 
RRECEDING BAGE BLANK NOT FLMED

\author{
GEODETIC RESULTS FROM \\ ISAGEX DATA \\ J. G. Marsh \\ Goddard Space Flight Center \\ Greenbelt, Maryland \\ B. C. Douglas* \\ D. M. Walls \\ Wolf Research and Development Corporation \\ Riverdale, Maryland 20840
}

\begin{abstract}
Laser and camera data taken during the International Satellite Geodesy Experiment (ISAGEX) have been used in dynamical solutions to obtain center-of-mass coordinates for the AstroSoviet camera sites at Helwan, Egypt and Oulan Bator, Mongolia and East European camera sites at Potsdam, German Democratic Republic and Ondrejov, Czechoslovakia. The results are accurate to about $20 \mathrm{~m}$ in each coordinate. The orbit of PEOLE $\left(i=15^{\circ}\right)$ has also been determined from ISAGEX data and mean Kepler elements suitable for geodynamic investigations are presented.
\end{abstract}

*Presently with the National Oceanic and Atmospheric Administration/National Ocean Survey, Rockville, Maryland. 


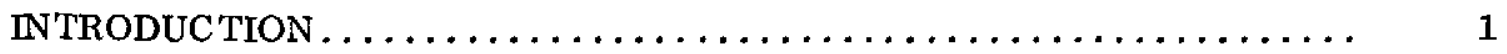

DYNAMICAL SOLUTIONS FOR STATION COORDINATES ............ 1

EVALUATION OF STATION COORDINATES ................ 4

MEAN ELEMENTS OF PEOLE $\ldots \ldots \ldots \ldots \ldots \ldots \ldots \ldots \ldots \ldots \ldots, 9$

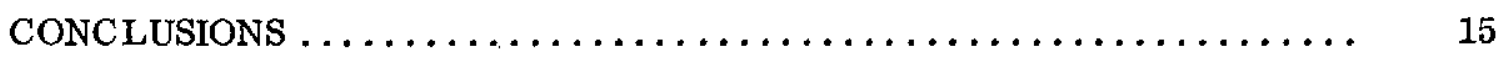

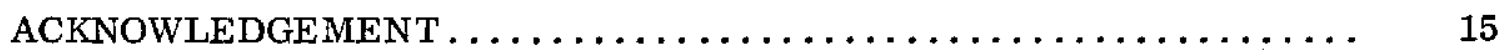

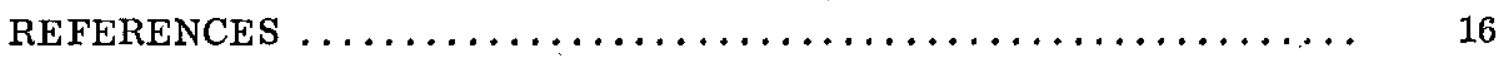

\section{ILLUSTRATIONS}

Figure

$\underline{\text { Page }}$

1 Locations of Stations Which Collected Data During the International Satellite Geodesy Experiment .............

2 Residuals from Simultaneous Observation of GEOS-1 by Cameras at Dionysos, Greece, (G), and Helwan,

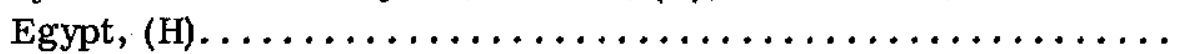

3 Residuals from Simultaneous Observation of GEOS-1 by Cameras at Helwan, Egypt, (H), and Dezeit, Ethiopia, (D).....

4 Residuals from Simultaneous Observation of GEOS-2 by Cameras at Haute Provence, France, (P), Zimmerwald, Switzerland $(\mathrm{Z})$, and Ondrejov, Czechoslovakia, $(\mathrm{O}) \ldots \ldots \ldots$

$5 \quad$ Residuals from Simultaneous Observation of GEOS-2 by Cameras at Ondrejov, Czechoslovakia, (O), and

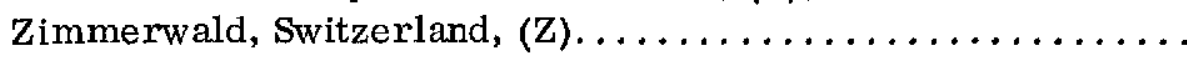




\section{ILLUSTRATIONS (Continued)}

Figure

Page

6 Mean Semi-Major Axis PEOLE-ISAGEX............. 12

7 Mean Eccentricity PEOLE-ISAGEX ............... 13

8 Residual Eccentricity with the SAO 1969 Standard Earth...... 13

\section{TABLES}

Table

Page

1 Summary of Astro-Soviet and East Europe Camera Data

Used in Dynamical Computations . . . . . . . . . . . . .

$2 \quad$ Orbital Arcs Used in Dynamic Solutions . . . . . . . . . . . . 5

$3 \quad$ Astro-Soviet and East European Station Coordinate Values ... $\quad 6$

4. Mean Orbital Elements for PEOLE in $1971 \ldots \ldots \ldots \ldots \ldots \ldots$ 
GEODETIC RESULTS FROM

ISAGEX DATA

\section{INTRODUCTION}

The ISAGEX experiment was initiated by the French Centre National d'Etudes Spatiales (CNES) in the autumn of 1969 through a proposal for an international laser and photographic campaign on satellites equipped with laser reflectors.

The ISAGEX experiment was endorsed by the COSPAR XIIIth General Assembly, Leningrad, 1970. The objective of the program was to collect a set of homogeneous and well distributed precise laser and camera satellite observations for the purposes of dymamic and geometric geodesy. The experiment involved seventeen countries and over fifty tracking stations. The data gathering portion of the experiment extended from December 1970 to September 1971.

The results of a dynamical solution which combined ISAGEX laser data with the optical and laser tracking data recorded during the National Geodetic Satellite Program (NGSP) and the CNES/SAO 1968 Observing Program have been reported previously by Marsh, et al. (1973). This solution provided coordinates for over 70 globally distributed tracking stations. Also very preliminary analyses of Astro-Soviet and East European camera data received as of May 1973 were reported by Marsh, Douglas and Klosko (1973b). The present paper represents a continuation of the analyse of the ISAGEX data using the laser and optical data available as of May 1974 to refine coordinates for the camera stations.

\section{DYNAMICAL SOLUTIONS FOR STATION COORDINATES}

The orbital and station coordinate recovery solutions were derived through the use of the GEODYN program (Martin, 1972) on the GSFC IBM 360/95 computer. GEODYN is a multiple arc, multiple satellite orbit and geodetic parameter estimation system based upon Cowell-type numerical integration techniques. Model parameters included luni-solar gravitational perturbations, solar radiation pressure, the Jacchia Model Atmosphere (1965, 1968, 1970, 1971) for drag computation, BIH polar motion and UTI data, and the GEM-1 gravity model (Lerch, et al. 1972) modified by the use of the resonant coefficients from the SAO 1969 S.E. II (Gaposchkin and Lambeck, 1970). This gravity model was used to insure consistency with the GSFC 1973 solution.

In the present effort, we have been primarily concerned with computation of orbital residuals from the Astro-Soviet and Eastern European data and a 
dynamical adjustment of the coordinates for these sites since data from these stations have not previously been available. The stations are:
ASTRO-SOVIET
EAST EUROPEAN
Oulan Bator, Mongolia
Ondrejov, Czechoslovakia
Helwan, Egypt
Potsdam, German Democratic Republic

The Astro-Soviet instruments were the AFU-75 tracking cameras and the East European stations used the Zeiss SBG camera. Figure 1 shows the locations of these stations, along with the other stations which participated in the ISAGEX. Table 1 presents a summary of the data used from these four stations, along with the RMS values of the residuals in the solutions. Data was contributed by several other Astro-Soviet and East European camera stations but were not analyzed since sufficient numbers of observations were not available for dynamical orbit computations. However, the data could be used in geometric analyses.

These data were preprocessed with corrections applied in accordance with the information provided in ISAGEX Report No. 16, "Data Handling Booklet" (Brachet 1973). In the case of the Astro-Soviet data, we applied corrections for annual and diurnal aberration and parallactic refraction; precession and nutation were applied to convert from the reference system with a mean equator and

Table 1

Summary of Astro-Soviet and East Europe Camera Data Used in Dynamical Computations

\begin{tabular}{|l|rc|cc|}
\hline \multirow{2}{*}{ Station } & \multicolumn{2}{|c|}{ Right Ascension* ( $\alpha)$} & \multicolumn{2}{c|}{ Declination ( $\delta)$} \\
\cline { 2 - 5 } & No. & R.M.S. & No. & R.M.S. \\
\hline Oulan Bator, Mongolia & 27 & 3.0 arc sec & 29 & 4.2 arc sec \\
Helwan, Egypt & 46 & 2.9 arc sec & 47 & 2.8 arc sec \\
Ondrejov, Czechoslovakia & 32 & 3.5 arc sec & 32 & 6.0 arc sec \\
Potsdam, German & & & & \\
$\quad$ Democratic Republic & 25 & 4.0 arc sec & 26 & 4.6 arc sec \\
\hline
\end{tabular}

* Right Ascension Residuals have been multiplied by $\cos \delta$. 

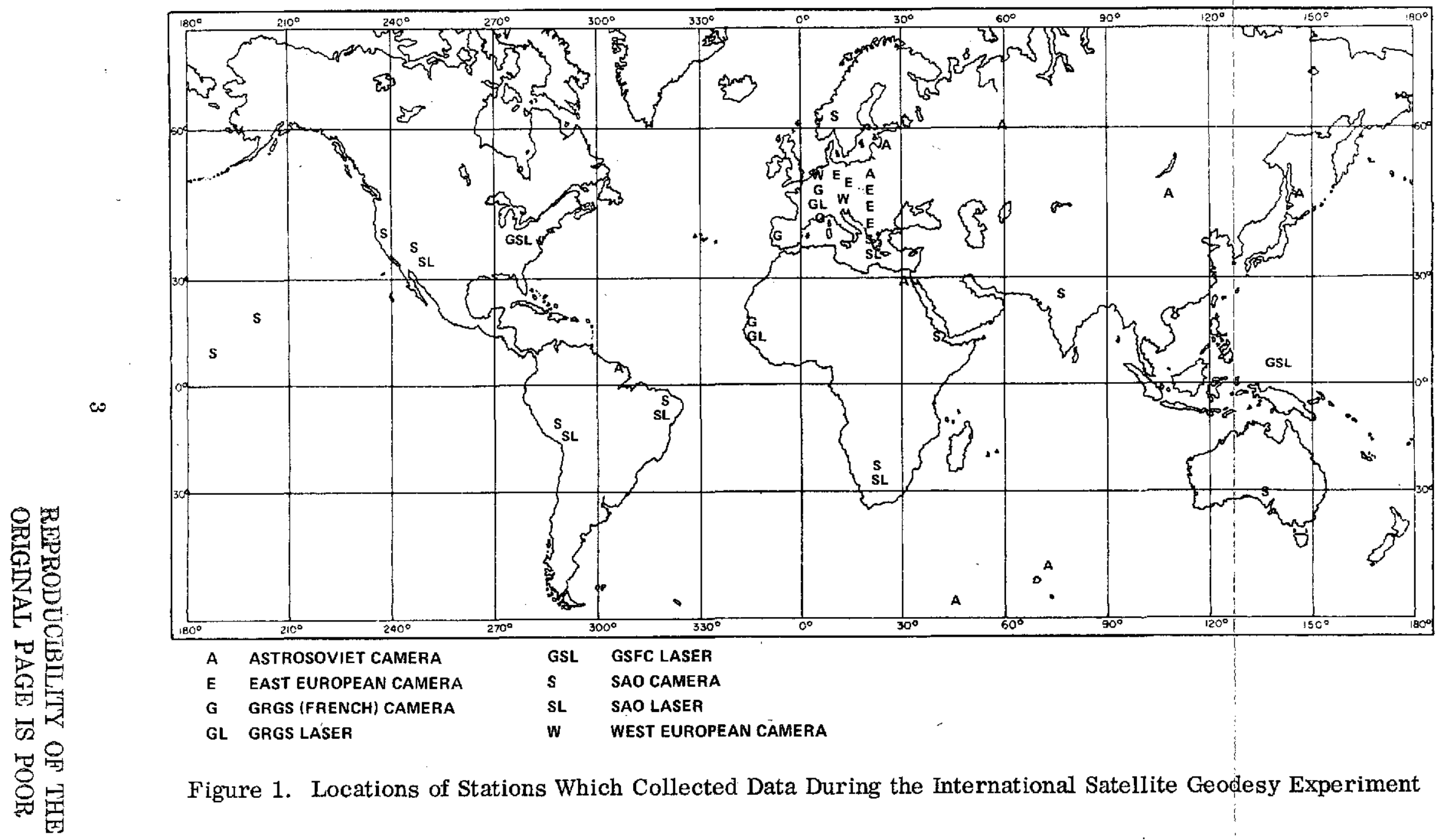

Figure 1. Locations of Stations Which Collected Data During the International Satellite Geodesy Experiment 
equinox of 1950.0 to a true of date system. The passive observation time tags were converted from USSR UT1 time to U.S. Naval Observatory (USNO) UTC time.

Corrections for annual and diurnal aberration were already applied to the data from Potsdam (1181) and Ondrejov (1147). We applied parallactic refraction to the Ondrejov data. The passive observation times for these data were converted from the BIH UTC system to the USNO UTC system.

In this solution, coordinates for the ISAGEX lasers and other cameras were held fixed at the values derived earlier by Marsh, et al., (1973). Thus, these new coordinates were determined from combined laser/optical reference orbits.

In the interest of efficient use of the computer, and since little overlap existed in the data, separate multi-arc solutions were made for each of the 4 site locations. Table 2 presents the arcs used in these solutions. Note that the solution for Helwan consisted of GEOS-1 data alone. GEOS-2 data could not be used because of large inconsistencies. If this problem could be solved, the solution would probably be significantly improved. In contrast, only GEOS-2 data (flashes) could be used for the Ondrejov solution, since there was a problem of timing system fluctuations as large as $7 \mathrm{~ms}$ for passive satellites at this station.

\section{EVALUATION OF STATION COORDINATES}

Table 3 presents the results obtained from this investigation and those provisional values given in ISAGEX Report No. 7 (Brachet, 1970). Differences between the provisionally available coordinates and the new values range from a few tens of meters to a few hundred meters.

The largest error source in this analysis is due to uncertainty in the modeling of the Earth's gravity field. As a means of assessing the magnitude of this error, the solutions were computed using the SAO 1969 (Gaposchkin and Lambeck, 1970) gravity model as well as the GSFC GEM-1 model mentioned earlier. The differences in the adjusted latitude and longitude coordinates were less than 20 meters in every case, while the height coordinate differences were less than 10 meters. Since the GEM-1 model gave a lower (by almost a factor of two) residual rms it is concluded that the GEM-1 solution is more accurate. Thus, the coordinate errors due to gravity model uncertainty are probably less than the differences in the two sets of coordinates and are assessed as less than 20 meters in latitude and longitude and less than 10 meters in height.

An initial height comparison at Oulan Bator indicated a difference on the order of 1400 meters between the dynamically derived value and the value of $175 \mathrm{~m}$ provided in the ISAGEX Report No. 7 (Brachet, 1970). Further checking with the 
Table 2

Orbital Arcs Used in Dynamic Solutions

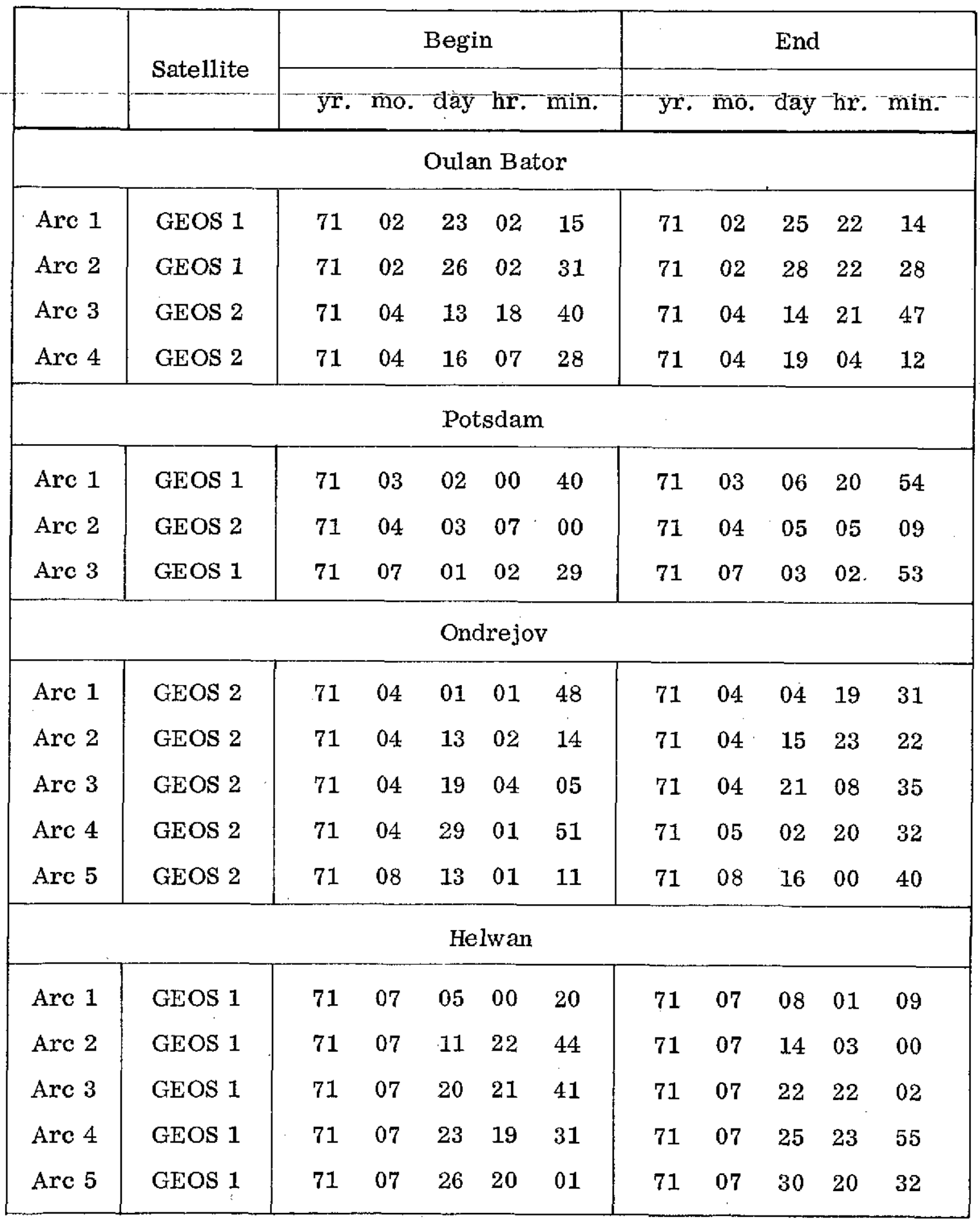


Table 3

Astro-Soviet and East European Station Coordinate Values

\begin{tabular}{|c|c|c|c|c|c|c|c|c|}
\hline \multirow{4}{*}{$\begin{array}{c}\text { Station } \\
\begin{array}{c}\text { Oulan Bator, } \\
\text { Mongolia }\end{array}\end{array}$} & & \multicolumn{3}{|c|}{$\begin{array}{c}\text { Latitude } \\
\text { (Deg, Min, Sec) }\end{array}$} & \multicolumn{3}{|c|}{$\begin{array}{l}\text { Longitude (E.) } \\
\text { (Deg, Min, Sec) }\end{array}$} & \multirow{2}{*}{$\frac{\begin{array}{c}\text { Height } \\
\text { (Meters) }\end{array}}{1540}$} \\
\hline & New Value & 47 & 51 & 55.1 & 107 & 3 & 10.7 & \\
\hline & Old Value* & 47 & 51 & 56 & 107 & 3 & 00 & 1505 \\
\hline & Difference & & & .9 & & & 10.7 & 35 \\
\hline \multirow[t]{3}{*}{ Helwan, Egypt } & New Value & 29 & 51 & 31.6 & 31 & 20 & 32.5 & 97 \\
\hline & Old Value* & 29 & 51 & 31.1 & 31 & 20 & 28.05 & 120 \\
\hline & Difference & & & .5 & & & 4.45 & 23 \\
\hline \multirow{3}{*}{$\begin{array}{l}\text { Ondrejov, } \\
\text { Czechoslovakia }\end{array}$} & New Value & 49 & 55 & 15.8 & 14 & 47 & 55.4 & 525 \\
\hline & Old Value* & 49 & 55 & 19.4 & 14 & 48 & 3.9 & 537 \\
\hline & Difference & & & 3.6 & & & 8.5 & 12 \\
\hline \multirow[t]{3}{*}{ Potsdam, GDR } & New Value & 52 & 22 & 49.7 & 13 & 3 & 54.1 & 147 \\
\hline & Old Value* & 52 & 22 & 51.4 & 13 & 3 & 58.8 & 136 \\
\hline & Difference & & & 1.7 & & & 4.7 & 11 \\
\hline
\end{tabular}

*From Brachet, 1970.

Defense Mapping Agency/Topographic Command (Niska, 1974) revealed that the MSL height should be $1550 \mathrm{~m}$. Thus using a geoid height of -45 meters (Marsh and Vincent, 1974) results in an ellipsoidal height of $1505 \mathrm{~m}$ or a difference of 35 meters with respect to the dynamic value.

An additional comparison was possible for the height coordinate at Potsdam since a value for the surveyed height above mean sea level (MSL) was provided. To this value of 109 meters, the geoid height of 27 meters from the GEM-6 detailed gravimetric geoid (Marsh and Vincent, 1974) was added resulting in an implied height above the reference ellipsoid of 136 meters, 11 meters less than the value recovered dynamically. This level of agreement is considered good since the 11 meter difference includes errors in the dynamical recovery, MSL survey errors, and errors in the geoid.

The quality of simultaneous data is important to consider. Figures 2 and 3 show the residuals in right ascension times cosine declination $(\alpha \cos \delta)$ and declination ( $\delta$ ) for typical simultaneous passes of Helwan with Dionysos, Greece and with Debra Zeit (DEZEIT), Ethiopia. The consistency is generally very good, 

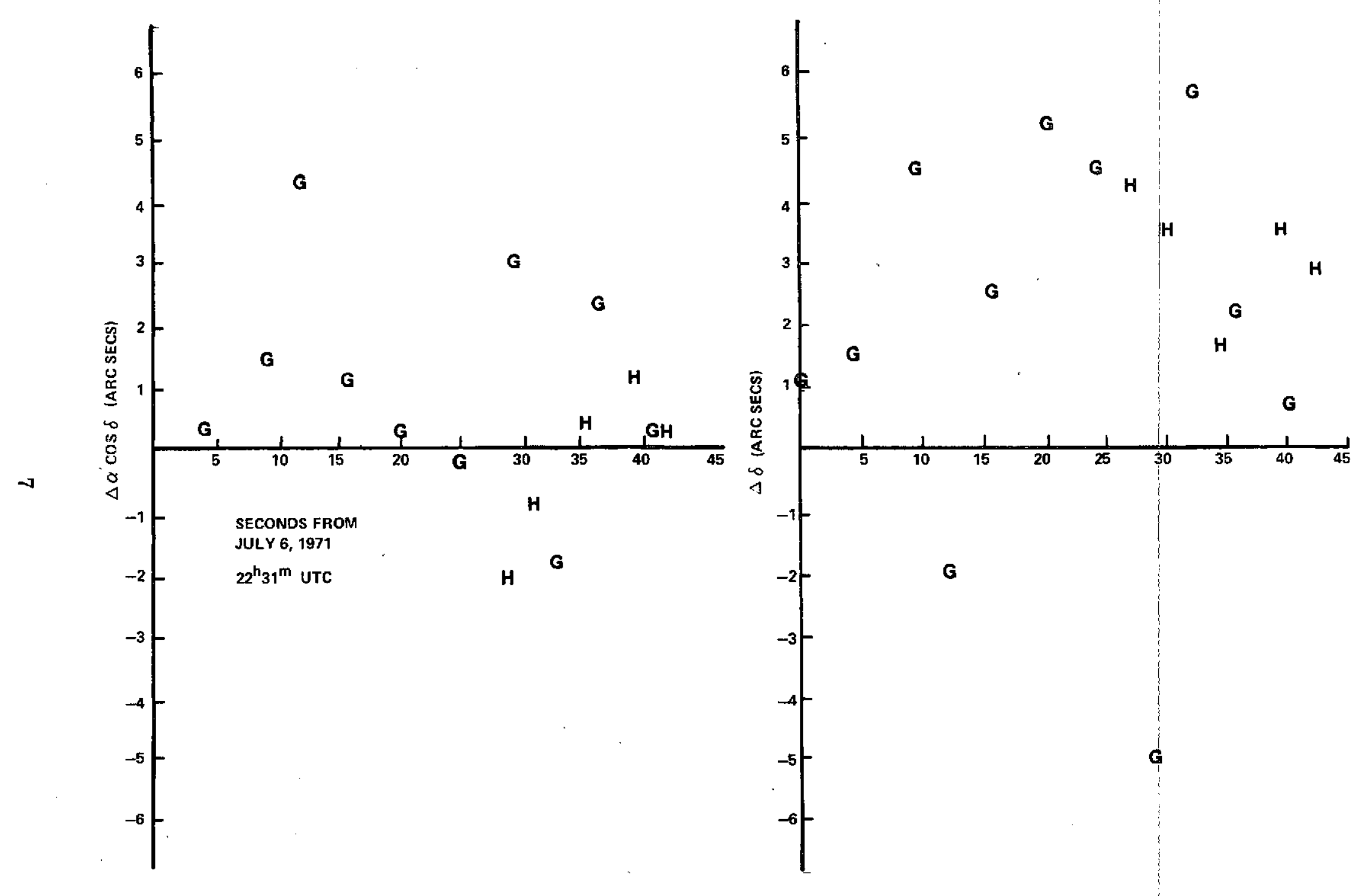

Figure 2. Residuals from Simultaneous Observation of GEOS-1 by Cameras at Dionysos, Greece, (G), and Helwan, Egypt, (H) 
$\infty$
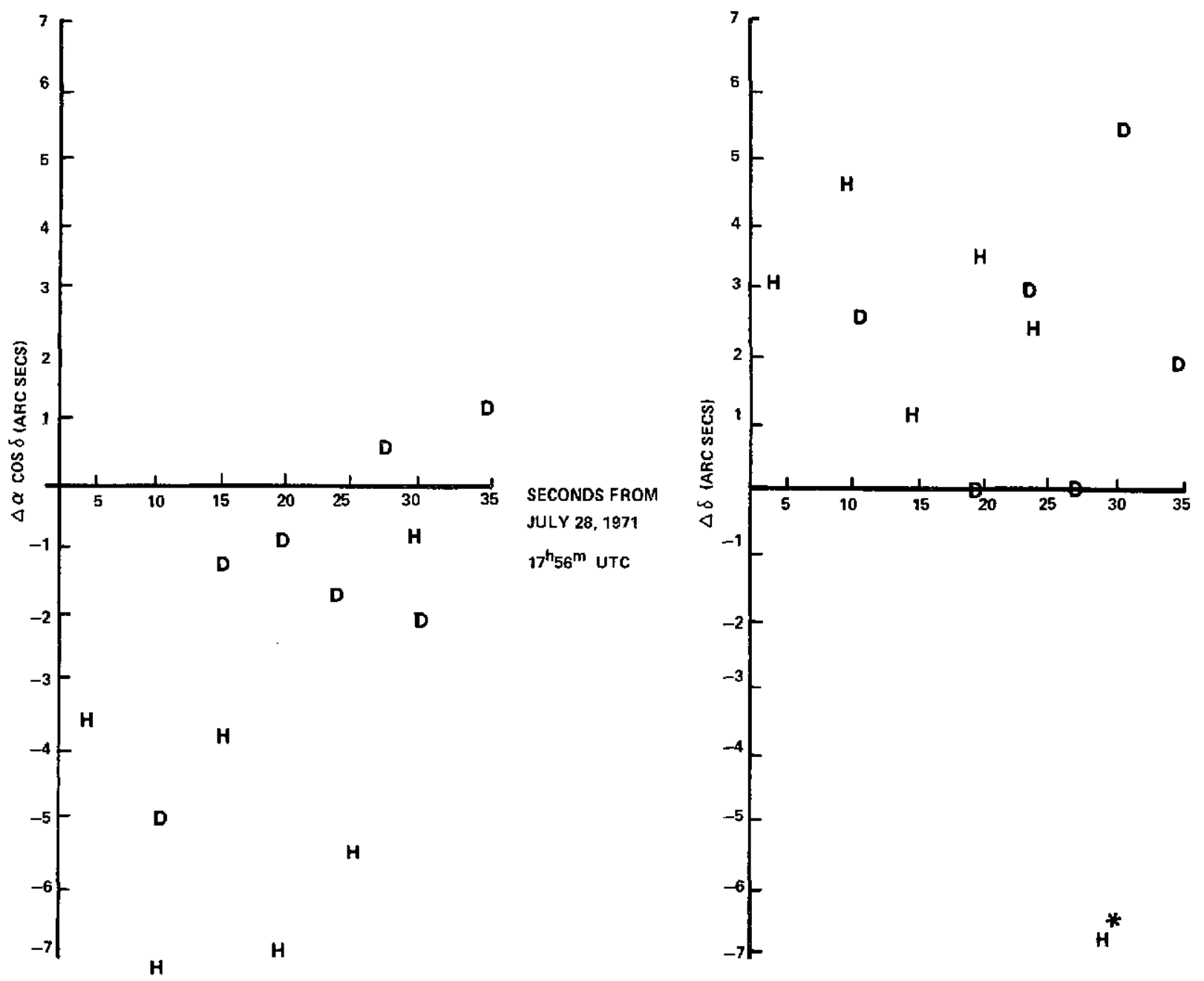

* edited from solution

Figure 3. Residuals from Simultaneous Observation of GEOS-1 by Cameras at Helwan, Egypt, (H) and Dezeit, Ethiopia, (D) 
except for the $\alpha \cos \delta$ residuals in Figure 3. The inconsistency is about 3 arc seconds between the centroid of the Helwan residuals and the centroid of the DEZEIT residuals.

Figures 4 and 5 show residuals for simultaneous tracking of Ondrejov with Haute Provence and/or Zimmerwald. The consistency is excellent, small average differences of only the order of one arc second appearing.

\section{MEAN ELEMENTS OF PEOLE*}

During 1971, osculating orbital elements for PEOLE were determined at 4-6 day intervals to provide prediction data for the GSFC laser at Guam as part of the International Satellite Geodesy Experiment. The orbits were determined almost entirely from CNES and NASA Minitrack data, with occasional passes of GSFC laser data from Guam, CNES laser data from Dakar, Senegal and SAO laser data from Arequipa, Peru and Natal, Brazil also employed. Because of the low inclination of the orbit and resultant diminished geopotential perturbations, the orbits determined from the Minitrack data alone are surprisingly precise. The uncertainty of the elements is much lower than the amplitudes of the orbit variations of interest.

The orbit of PEOLE is especially interesting for atmospheric and geopotential investigations. The mean decay rate of the semi-major axis is about $30 \mathrm{~m} / \mathrm{day}$, but there is considerable variation over the year. The perturbations due to odd zonal harmonics are also very large. Solar tidal perturbations may also be perceptible in the inclination.

We have prepared mean orbital elements of PEOLE from the osculating elements by the combined analytic-numerical technique developed by Douglas, Marsh, and Mullins (1972). The method involves the analytical removal of all large short periodic perturbations followed by a numerical averaging over 1 day to remove remaining small high frequency effects. Thus all long periodic and secular effects remain in the mean elements.

Figure 6 shows the mean semi-major axes obtained from the orbital fits. The SAO 1969 Standard Earth (Gaposchkin and Lambeck, 1970) gravity model was used in the orbit determinations. To get the most accurate orbits possible, the drag coefficient was adjusted in each orbital arc. When the mean elements were computed, the appropriate drag coefficient was used for each computation. Thus the mean elements given here are an accurate portrayal of the evolution of the orbit.

\footnotetext{
*Presented to the Symposium on Satellite and Terrestial Triangulation, Graz, Austria, May 1972.
} 

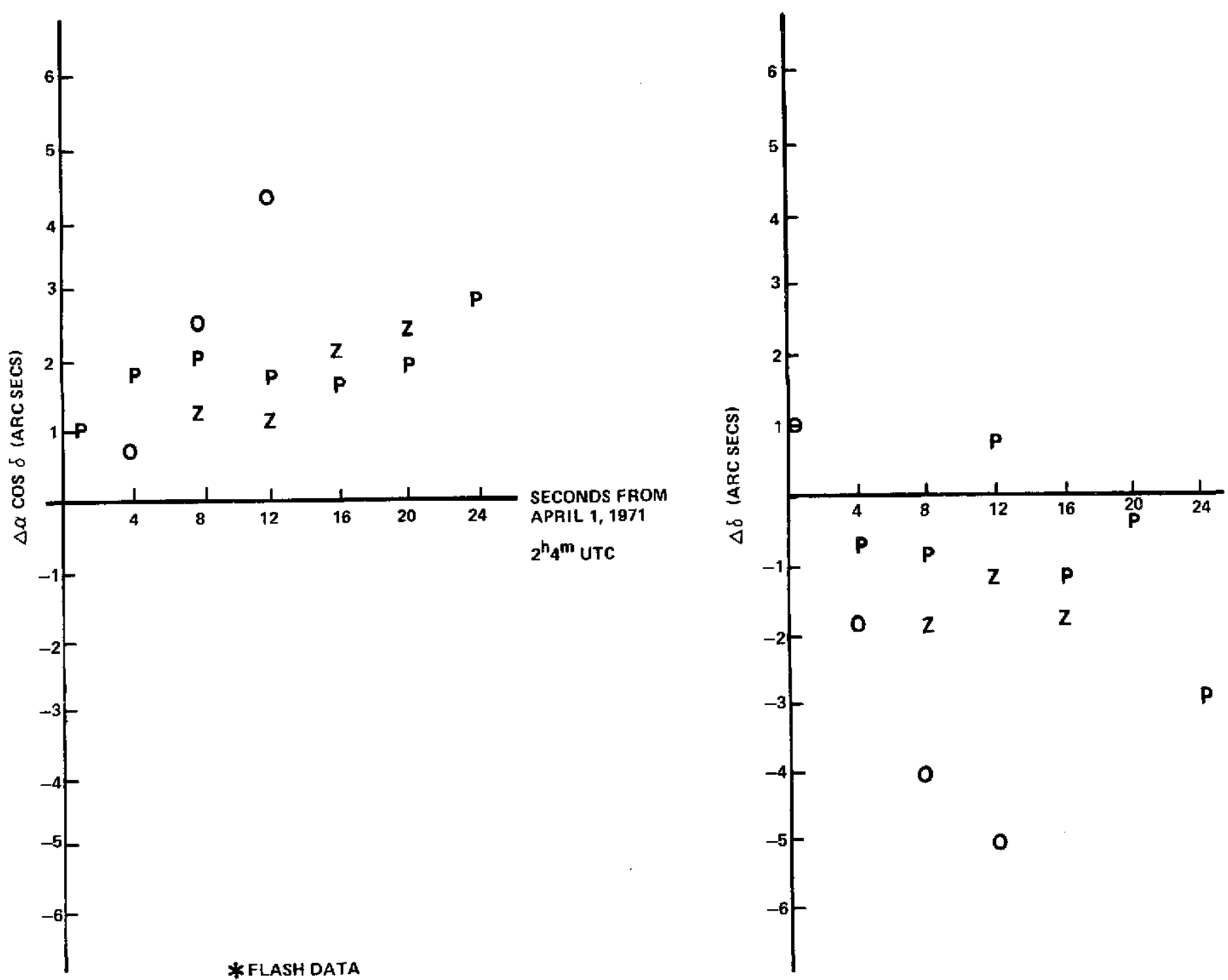

Figure 4. Residuals from Simultaneous Observation* of GEOS-2 by Cameras at Haute Provence, France, (P), Zimmerwald, Switzerland, (Z), and Ondrejov, Czechoslovakia, (O) 

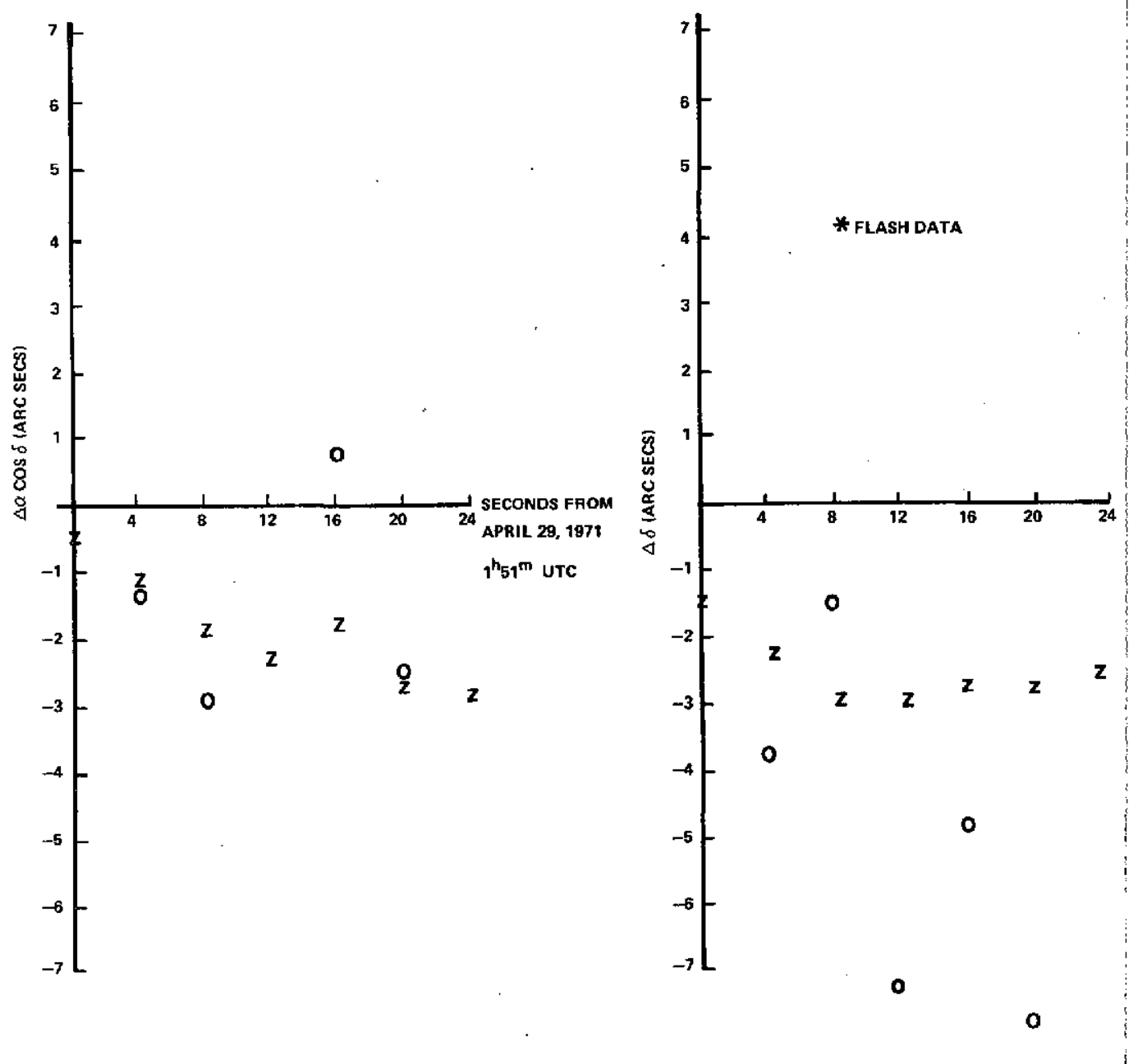

Figure 5. Residuals from Simultaneous Observation* of GEOS-2 by Cameras at Ondrejov, Czechoslovakia, (O) and Zimmerwald, Switzerland, (Z) 


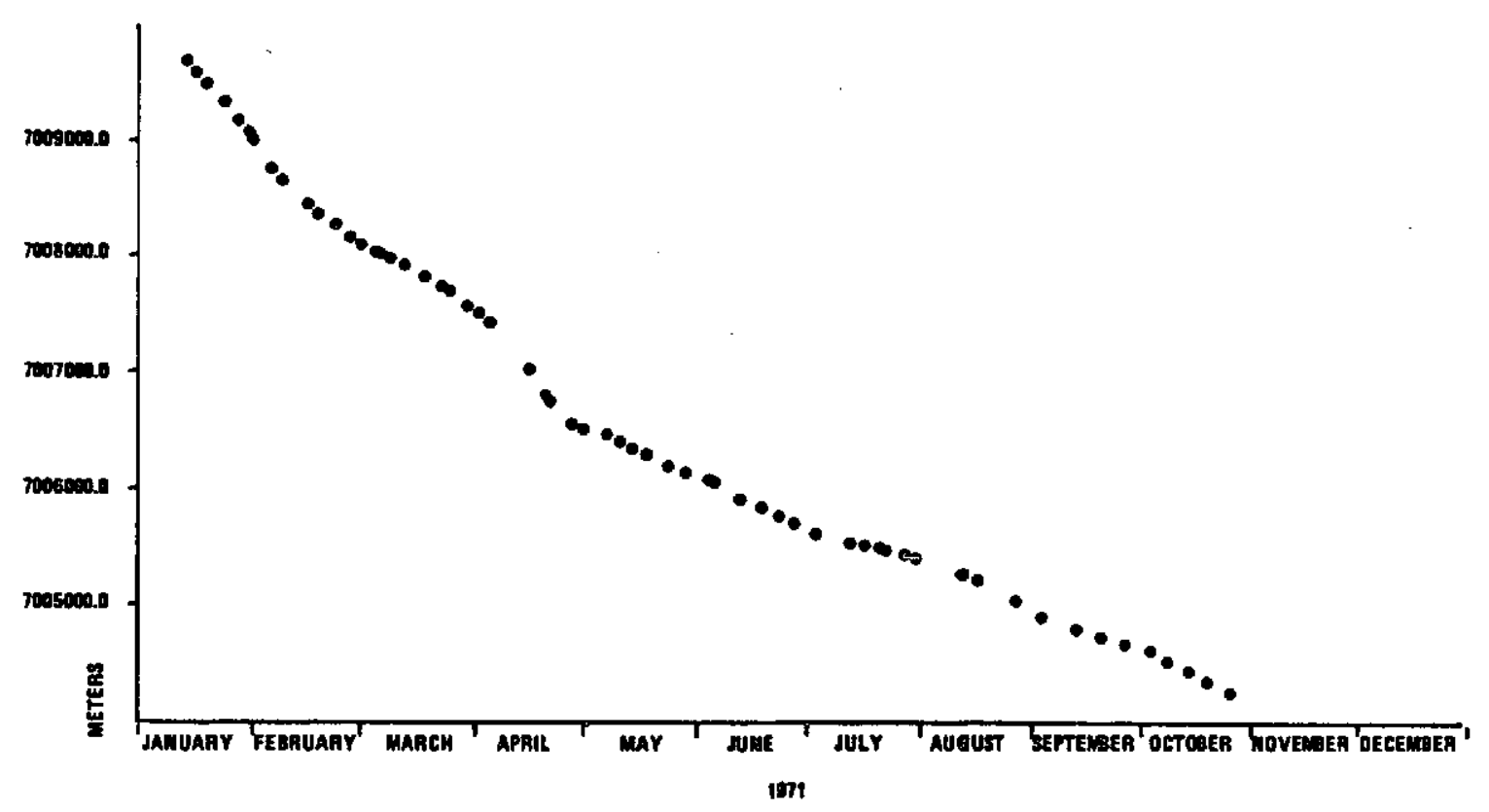

Figure 6. Mean Semi-Major Axis PEOLE-ISAGEX

As is evident in Figure 6, the PEOLE orbit decays rapidly, up to $1 \mathrm{Km}$ per month. This can be a serious matter for geodetic investigations unless the drag perturbation can be accurately modeled. Preliminary results show that if the drag coefficient $C_{D}$ is allowed to adjust and the atmospheric density is modeled by the Jacchia model atmosphere (Jacchia 1965, 1968), the unmodeled part of the decay is only a few hundred meters out of a total decay of about $12 \mathrm{Km}$ during the year.

Figure 7 shows the mean eccentricities of the PEOLE orbit. Clearly visible are the secular decay due to atmospheric drag and the approximately 28 day oscillation due to the odd zonal harmonics. Figure 8 shows the residual eccentricity for the first six months of 1971 after removal of atmospheric drag effects by the Jacchia model, zonal harmonic effects by the SAO 1969 Standard Earth, and luni-solar perturbations. About $80 \%$ of the odd zonal harmonic effects have been accounted for, but a discernable unmodeled 28 day effect remains. The precision of the mean eccentricities is probably better than one part in $10^{5}$, which is consistent with the observed dispersion in the semi-major axis.

Table 4 presents all of the mean elements of PEOLE in tabular form. The time system is UTC. It is hoped that these elements will prove useful to other investigators. 


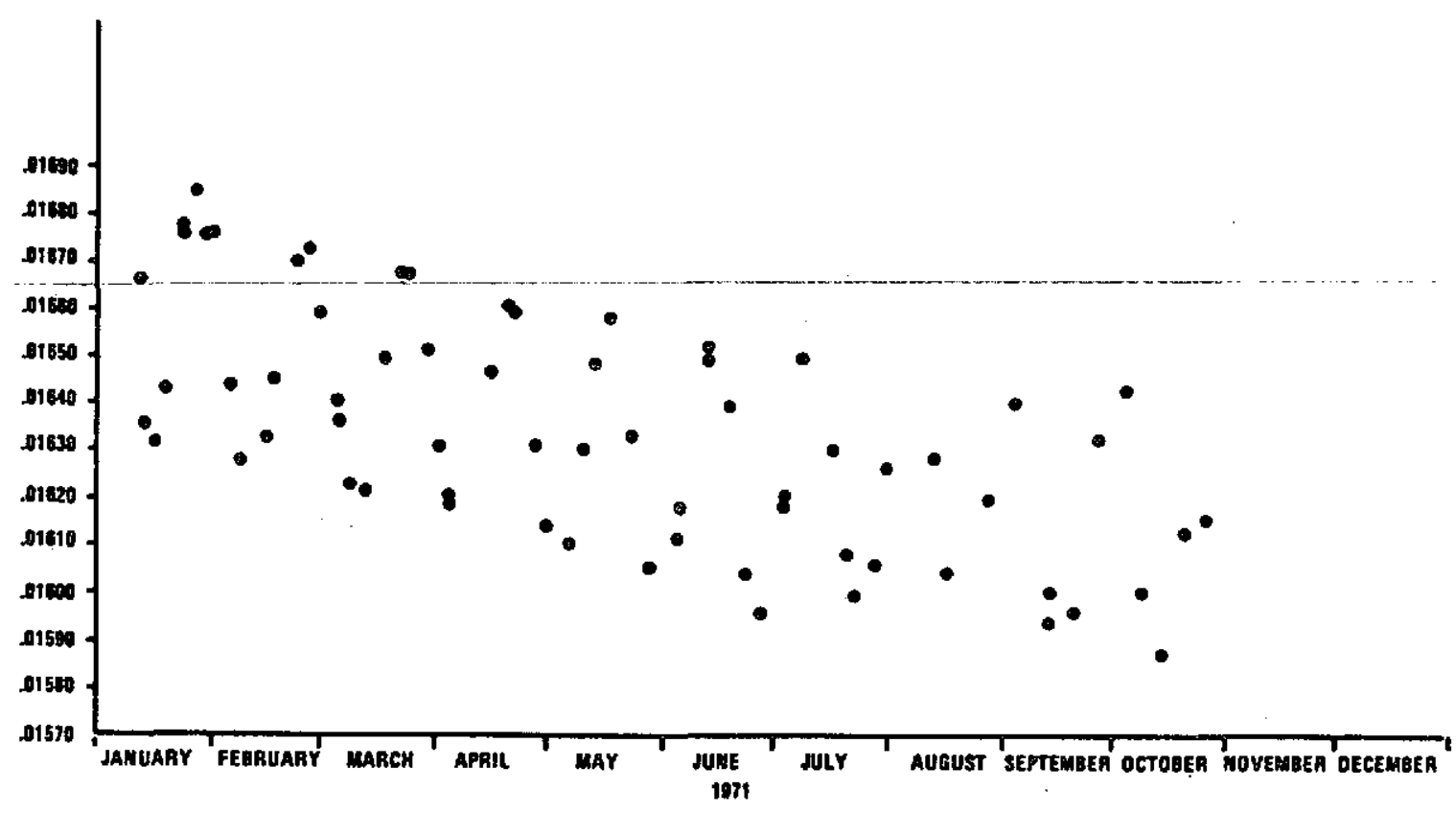

Figure 7. Mean Eccentricity PEOLE-ISAGEX

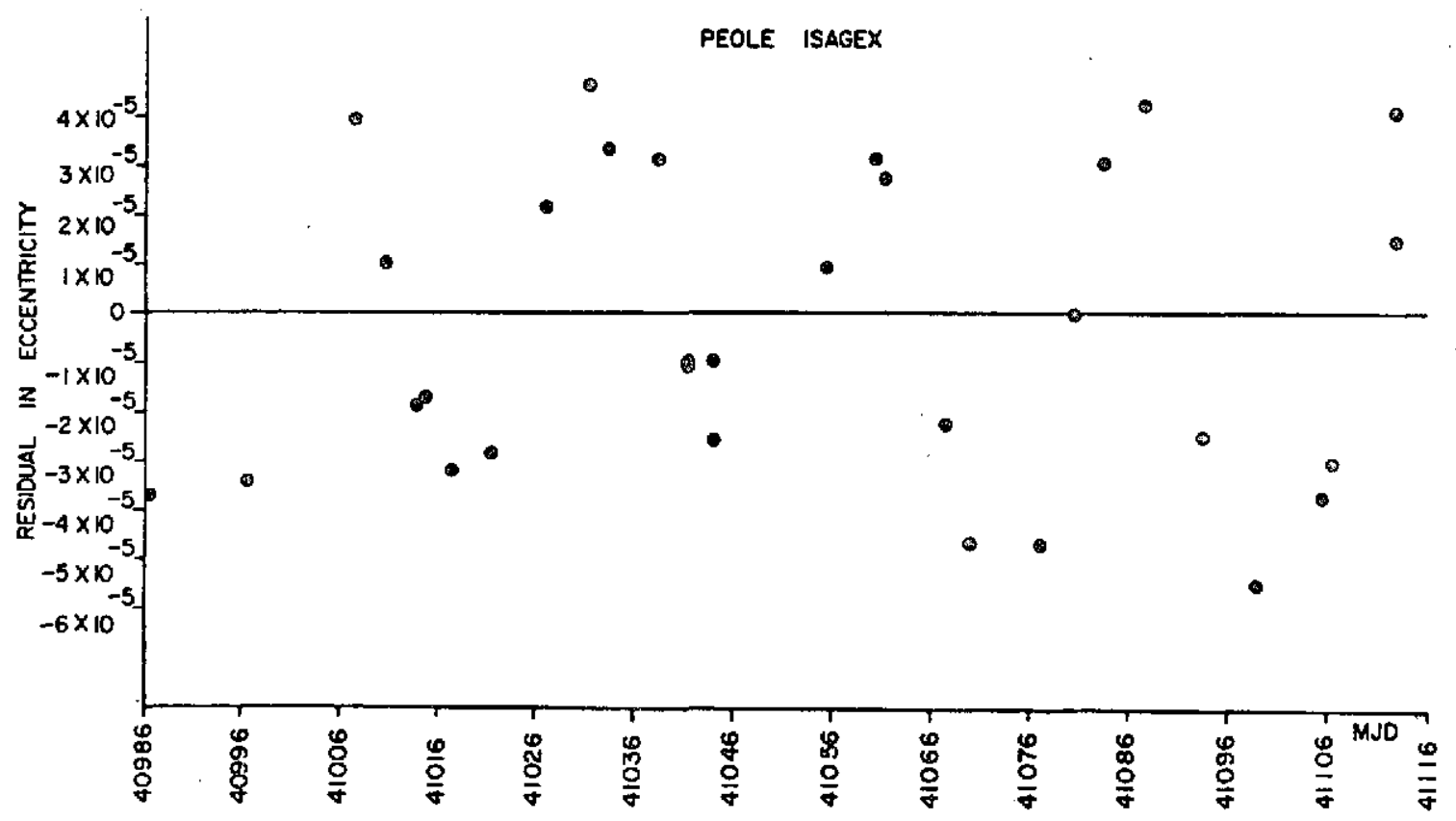

Figure 8. Residual Eccentricity with the SAO 1969 Standard Earth 
Table 4

Mean Orbital Elements for PEOLE in 1971

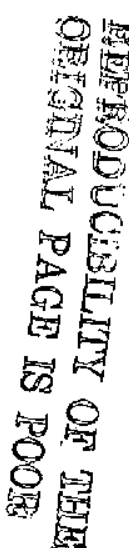

\begin{tabular}{|c|c|c|c|c|c|c|}
\hline TIME (MJD) & A (METERS) & $\mathbf{E}$ & 1 (OEGGREES) & W (DEGREES) & N (DEGBEES) & M (OEGREES) \\
\hline $\begin{array}{l}40980.462777719 \\
40969.598587931\end{array}$ & $\begin{array}{l}7009597.85794 \\
7009496.24795\end{array}$ & $\begin{array}{l}.016318072 \\
.016431391\end{array}$ & $\begin{array}{l}29.005041 \\
15.003364\end{array}$ & $\begin{array}{l}284.502345 \\
325.512804\end{array}$ & $\begin{array}{l}329.983986 \\
309.136896\end{array}$ & $\begin{array}{r}272.467983 \\
72.322104\end{array}$ \\
\hline 40980.535451350 & 7009065.18692 & .316760687 & 15.002480 & 109.920721 & 231.911210 & 73.sokera \\
\hline 40981.527499936 & 7008989.37515 & .016763530 & 15.004165 & 122.806151 & 224.907550 & 323.522267 \\
\hline & 7008700.49327 & .016439371 & 15.005973 & 188.681498 & 195.138338 & 347.559913 \\
\hline 40996.691770807 & 7008434.12950 & .016328953 & 15.006885 & 324.957811 & 110.257080 & 194.275450 \\
\hline 41007.739095800 & 7008153.84322 & .036731696 & 15.005039 & 109.975350 & 42.257647 & 89.774218 \\
\hline $\begin{array}{l}41010.823229133 \\
41013.875349697\end{array}$ & & .J16596132 & 15.005453 & 152.325923 & $2 t .707355$ & 325.827605 \\
\hline $\begin{array}{l}41013.875349697 \\
41014.720844875\end{array}$ & $\begin{array}{l}7008 C 29.01813 \\
7008023.29546\end{array}$ & & 15.006312 & $\begin{array}{l}193.634857 \\
201.025101\end{array}$ & $\begin{array}{l}359.409315 \\
353.521445\end{array}$ & $\begin{array}{r}45.245826 \\
235.94925 ?\end{array}$ \\
\hline 41017.613136546 & 7007979.37785 & $\begin{array}{r}.016364875 \\
.016233129\end{array}$ & $\begin{array}{l}15.005303 \\
15.004977\end{array}$ & $\begin{array}{l}201.825101 \\
240.499837\end{array}$ & $\begin{array}{l}353.521845 \\
333.352564\end{array}$ & $\begin{array}{l}235.949252 \\
192.016428\end{array}$ \\
\hline & $7007932.57 c 90$ & .016218049 & $15.003 \mathrm{cBs}$ & 293.677443 & 305.802925 & 23.165382 \\
\hline 41027.352175889 & 7007828.91640 & .016499448 & 15.005339 & 10.045811 & 265.786622 & 22.221106 \\
\hline $41031.51 \csc 222$ & 7007731.82794 & .016680768 & 15.003418 & 65.226442 & 236.432323 & 150.427309 \\
\hline 41033,749305556 & 7007704.26232 & .016682622 & 15.003252 & 94.608971 & 225.803376 & 212.8320 .62 \\
\hline & $\begin{array}{l}7007579.79792 \\
7007510.57854\end{array}$ & .016520497 & 15.003250 & 158.651671 & $18 x .5 n 23 n 5$ & $16 n .731429$ \\
\hline $\begin{array}{l}41641.655972223 \\
41041.665972223\end{array}$ & $\begin{array}{l}7007510.57854 \\
7007511.13861\end{array}$ & & 15.004321 & $\begin{array}{l}198.360457 \\
198.348222\end{array}$ & 165.572664 & 323.496117 \\
\hline & 7007430.93191 & $\begin{array}{l}.016316789 \\
.016207604\end{array}$ & 15.003988 & 198.348222 & 165.572256 & 323.906105 \\
\hline 41044.073888958 & $7 C 07424.36241$ & $\begin{array}{l}.016207604 \\
.016191831\end{array}$ & 15.005617 & 230.469847 & $14 A .782850$ & 208.591952 \\
\hline 41055.707638889 & 7607612.27887 & $\begin{array}{l}.016191831 \\
.016473809\end{array}$ & $\begin{array}{l}15.007851 \\
15.007148\end{array}$ & 233.531730 & $14 R .7715 n 2$ & 208.532473 \\
\hline 41060.555995330 & 7006790.47464 & $\begin{array}{l}.016473809 \\
.016611171\end{array}$ & $\begin{array}{l}15.007148 \\
15.005030\end{array}$ & $\begin{array}{l}26.056569 \\
89.416583\end{array}$ & $\begin{array}{l}67.617400 \\
33.785076\end{array}$ & $\begin{array}{l}340.053476 \\
297.275156\end{array}$ \\
\hline 41061.567870335 & 7000748.11580 & .216600013 & $\begin{array}{l}15.005030 \\
15.004057\end{array}$ & $\begin{array}{r}89.410583 \\
102.517254\end{array}$ & 26.718476 & $\begin{array}{l}2.97 .275156 \\
296.26 .2663\end{array}$ \\
\hline 41067.566643483 & 7006553.0 .7894 & .016315249 & 15.005819 & 181.265120 & 344.851301 & 262.722309 \\
\hline 41070.505451365 & $7000 \div 29.29015$ & .016347889 & 15.006345 & 222.426074 & 324.341752 & 102.501160 \\
\hline 41076.937997651 & 7006457.96388 & .016109947 & 15.007621 & 306.899043 & 279.457015 & 222.535129 \\
\hline $\begin{array}{l}41080.521330984 \\
41083,737141183\end{array}$ & $\begin{array}{l}7005401.82527 \\
7006304.99 \times 85\end{array}$ & $\begin{array}{l}.01030965 c \\
\Rightarrow 16489700\end{array}$ & $\begin{array}{l}15.008408 \\
15.005768\end{array}$ & $\begin{array}{r}354.695800 \\
37.046092\end{array}$ & $\begin{array}{l}254.45919 \mathrm{~A} \\
232.010 \mathrm{AB2}\end{array}$ & $\begin{array}{l}261,589177 \\
140.410192\end{array}$ \\
\hline $\begin{array}{l}41083,737141183 \\
41087.7126 C 4132\end{array}$ & 7006300.71825 & .016589230 & 15.006053 & 88.985690 & 204.245469 & 113.253548 \\
\hline 41093.540972223 & 7006207.76799 & .216338391 & 15.004546 & 165.198842 & 263.546331 & 253.613233 \\
\hline 41098.707638389 & 7006166.71870 & .016058260 & 15.004907 & 234.026188 & 127.486425 & 102.151093 \\
\hline 41105.624305556 & 7006075.61479 & .016123877 & 15.006421 & 325.944392 & 79.204999 & $288.09 n 821$ \\
\hline $\begin{array}{l}41106.595486001 \\
41113.495305556\end{array}$ & 7006056.40525 & .016174233 & 15.006823 & 339.906843 & 72.427259 & 70.272318 \\
\hline $\begin{array}{l}411113.495305556 \\
41113.495305556\end{array}$ & 7005929.86731 & .016526877 & 15.007457 & 70.742412 & 24.221344 & 100.680570 \\
\hline & $\begin{array}{l}7005929.71787 \\
7005831.39543\end{array}$ & $\begin{array}{l}.016500672 \\
.316397185\end{array}$ & $\begin{array}{l}15.004844 \\
15.005168\end{array}$ & $\begin{array}{r}70.683683 \\
150.857124\end{array}$ & & \\
\hline $\begin{array}{l}41119.624305556 \\
41124.024305556\end{array}$ & & $\begin{array}{l}.016397185 \\
.016046345\end{array}$ & $\begin{array}{l}15.005168 \\
15.002939\end{array}$ & 217.156717 & $\begin{array}{l}341.457960 \\
306.558098\end{array}$ & 158.114630 \\
\hline 41128.749305556 & 2005713.31352 & .015760138 & 15.003575 & 272.469959 & 277.778438 & 210.203534 \\
\hline 41134.665972223 & 7005619.61580 & .016208890 & 25.005438 & 351.795978 & 236.458749 & 303.561178 \\
\hline 41134.665972223 & 7005619.47976 & .016191483 & 15.005103 & 351.826308 & 236.451812 & 103.526994 \\
\hline 41143.666574022 & 7005542.42048 & .0016502691 & 15.002993 & 109.867984 & 173.586867 & 257.678586 \\
\hline 41147.583240689 & 7005517.31855 & .016308187 & 15.001108 & 161.163059 & $14 k .232117$ & 290.272045 \\
\hline 41151.543310151 & 7005491.63513 & .016580811 & 15.001780 & 213.816710 & $11 A .5765 B 4$ & 173.824012 \\
\hline $\begin{array}{l}412060456,724507 \\
41232.159027801\end{array}$ & & $\begin{array}{l}.916007890 \\
.016007106\end{array}$ & $\begin{array}{l}15.007528 \\
15.004148\end{array}$ & $\begin{array}{l}221.425675 \\
201.475825\end{array}$ & & $\begin{array}{l}210.917568 \\
281.771183\end{array}$ \\
\hline $\begin{array}{l}41232.159027801 \\
41237.796035231\end{array}$ & $\begin{array}{l}7004522.15597 \\
7004429.07921\end{array}$ & $\begin{array}{l}.016007106 \\
.015879833\end{array}$ & $\begin{array}{l}15.004148 \\
15.003299\end{array}$ & 277.554388 & 236.125368 & 96.091651 \\
\hline $\begin{array}{l}41243.359455969 \\
41248.9 B 9837927\end{array}$ & 7004350.33496 & .016135797 & 14.988362 & 351.952758 & 197.311994 & 240.104514 \\
\hline 41248.989837927 & 7000243.73143 & .016164420 & 14.981067 & 65.708509 & $157.93040 \mathrm{AB}$ & 83.197875 \\
\hline
\end{tabular}




\section{CONCLUSIONS}

The new center of mass coordinates presented in this paper in combination with our previous (Marsh, et al., 1973) results give strong ties covering the Eurasian continent and northern and southern Africa. The mean orbital elements of PEOLE, determined from a combination of laser and Minitrack data, have already proven useful in geodynamic investigations (King Hele, 1973; Wagner, et al., 1974). All of these results demonstrate the value of properly coordinated cooperative programs.

\section{ACKNOWLEDGEMENT}

The authors acknowledge the help of Dr. J. A. O'Keefe of the Theoretical Studies Group at Goddard, and Mr. O. R. Niska and other personnel of the Department of Geodesy of the Defense Manning Agency/Topographic Center in researching the value for the surveyed height at Oulan Bator. 


\section{REFERENCES}

Brachet, G., "International Satellite Geodesy Experiment Plan," ISAGEX Report No. 7, CNES, November 1970.

Brachet, G., "Data Handling Booklet," ISAGEX Report No. 16, CNES, May 1973.

Douglas, B. C., Marsh, J. G., Mullins, N. E., "Mean Elements of GEOS-1 and GEOS-2," Celestial Mechanics 7, pp. 195-204, 1973.

Gaposchkin, E. M., and Lambeck, K., "1969 Smithsonian Standard Earth (II) ,"

SAO Special Report 315, Smithsonian Astrophysical Observatory, Cambridge, Massachusetts, 1970.

Jacchia, L. G., "Static Diffusion Models of the Upper Atmosphere with Empirical Temperature Profiles," SAO Special Report 170, 1965.

Jacchia, L. G., Campbell, I. G., Slowley, J. W., "Semi-Annual Density Variations in the Upper Atmosphere, 1958 to 1966," SAO Special Report 265, 1968.

Jacchia, L. G., "New Static Models of the Thermosphere and Exosphere with Empirical Temperature Profiles," SAO Special Report 313, 1970.

Jacchia, L. G., "Revised Static Models of the Thermosphere and Exosphere with Empirical Temperature Profiles," SAO Special Report 332, 1971.

King Hele, D. G., Cook, G. E., "Analysis of 27 Satellite Orbits to Determine Odd Zonal Harmonics in the Geopotential," RAE Technical Report 73153, December 1973.

Lerch, F. J., Wagner, C. A., Smith, D. E., Sandson, M. L., Brown, J. E., Richardson, J. A., "Gravitational Field Models for the Earth (GEM 1 and 2)," GSFC Document X-553-72-146, May 1972.

Marsh, J. G., Douglas, B. C., Klosko, S. M., "A Global Station Coordinate Solution Based Upon Camera and Laser Data - GSFC 1973," presented at the First International Symposium on the Use of Artificial Satellites for Geodesy and Geodynamics, Athens, Greece, May 1973, also NASA/GSFC Document $\mathrm{X}-592-73-171$, May 1973.

Marsh, J. G., Douglas, B. C., Klosko, S. M., "Analyses of Precision Reduced Optical Observations from the International Satellite Geodesy Experiment (ISAGEX)," GSFC Document X-590-73-340, November, $1973 \mathrm{~b}$. 
Marsh, J. G., Vincent, S., "Global Detailed Geoid Computation and Model Analysis," Geophysical Surveys 1, pp. 67-97, 1974.

Martin, T. V., "GEODYN Systems Operation Description," Wolf Research and Development Corporation Final Report on Contract NAS 5-11736-129, February 1972.

Niska, O. R., Defense Mapping Agency/Topographic Center, Department of Geodesy, Private Communication, 1974.

Wagner, C. A., Douglas, B. C., Williamson, R. G., "The Road Program," GSFC Document X-921-74-144, January 1974. 